\title{
FRICÇÕES DE UMA TRAMA PEDAGÓGICA: O CONHECIMENTO SE CONSTRÓI NO ENCONTRO COM O MUNDO
}

\section{FRICTIONS OF A PEDAGOGICAL PLOT: KNOWLEDGE IS CONSTRUCTED IN CONTACT WITH THE WORLD}

\author{
PEREIRA, Dilson Miklos ${ }^{1}$
}

\begin{abstract}
Apenas o que é minoritário tem potência de criação. O que é dominante não cria, apenas captura. ${ }^{2}$
\end{abstract}

\begin{abstract}
RESUMO
O artigo apresenta um recorte da pesquisa em curso no doutorado e integra uma das ações desenvolvidas no âmbito do Projeto Arqueologia de Saberes, Imagens e Afetos, uma experiência que aflora narrativas, imagens e sentidos no espaço da disciplina Arte e Educação, do Curso de Pedagogia, no Instituto Superior de Educação do Rio de Janeiro (ISERJ). A ação pedagógica oportunizada, em questão, foi a apropriação de um objeto prosaico da sociedade de consumo, um marcador de página que reproduz a imagem gráfica de uma obra da artista plástica e escritora Sonia Lins. Walter Benjamin, Mikhail Bakhtin, Fayga Ostrower e Gilles Deleuze, entre outros, iluminam o percurso, possibilitando uma leitura que evidencia uma estética do cotidiano. As narrativas discentes, que emergem dessa experiência estética e ética, revelam uma diversidade de olhares e capturas simbólicas. No cerne, o exercício de uma humanidade que contesta ações e valores que brutalizam o sujeito nos diversos contextos da vida.
\end{abstract}

PALAVRAS-CHAVE: formação de professores; arte; Walter Benjamin e Sonia Lins

\section{ABSTRACT}

The article presents a review of the current research in the doctorate and integrates one of the actions developed in the scope of the Project Archeology of Knowledge, Images and Affects, an experience that emulates narratives, images and senses in the space of the discipline Art and Education of the Pedagogy Course Of a higher education institution in the State of Rio de Janeiro. The pedagogical action in question was the appropriation of a prosaic object of consumer society, a text marker that reproduces the graphic image of a

1 Professor do curso de Pedagogia do Instituto Superior de Educação do Rio de Janeiro (ISERJ); Doutorando do Programa de Pós-Graduação em Educação da Universidade Federal do Estado do Rio de Janeiro (PPGEdu/UniRio). e-mail: dilson.miklos@gmail.com

${ }^{2}$ Autor desconhecido, Muro das Provocações, Museu de Arte Moderna do Rio de Janeiro (MAM-RJ), outubro de 2015. 
DOI: $10.12957 /$ e-mosaicos.2018.30124

work by the plastic artist and writer Sonia Lins. Walter Benjamin, Mikhail Bakhtin, Fayga Ostrower and Gilles Deleuze illuminate the course, enabling a reading that highlights an aesthetic of everyday life and the encounter with the other and the world. The student narratives, which emerge from this aesthetic and ethical experience, reveal a diversity of symbolic looks and captures. At the heart of the action lies the exercise of a humanity that challenges actions and values that brutalize the subject in the various contexts of life.

KeYwords: teacher training, aesthetics; experience; Sonia Lins

\section{UM CONTEXTO E SUAS VOZES} abertura:

Gilles Deleuze indica o modus operandi do percurso que se coloca em

É preciso pegar as coisas para extrair delas as visibilidades. E a visibilidade de uma época é o regime de luz, e as cintilações, os reflexos, os clarões que se produzem no contato da luz com as coisas. Do mesmo modo é preciso rachar as palavras ou as frases para delas extrair os enunciados (DELEUZE, 2013, p.124).

É no exercício de apropriação da ação do pensamento deleuziano e do encontro com as centelhas filosóficas de Walter Benjamin, Mikhail Bakhtin, Fayga Ostrower, entre outros, que um percurso pedagógico vai sendo desenhado e enunciados extraídos de uma experiência estética e ética ocorrida no contexto da disciplina Arte e Educação, ministrada no $1^{\circ}$ período, do Curso de Pedagogia, no Instituto Superior de Educação do Rio de Janeiro (ISERJ). ${ }^{3}$

Inspirado nesse movimento, que adquire expressão com as narrativas discentes que contam um processo de criação que nasce no encontro com o outro, que Bakhtin - pensador que compreende a realidade como um produto das ações no mundo e que encarna ideias que se situam nas zonas limítrofes - esclarece um ponto fundamental:

O sentido é potencialmente infinito, mas pode atualizar-se somente em contato com outro sentido (do outro), ainda que seja com uma pergunta do discurso interior do sujeito da compreensão. Ele deve sempre contatar com outro sentido para revelar os novos elementos da sua perenidade (como a palavra revela os seus significados somente no contexto). Um sentido atual não pertence a um (só) sentido mas tão somente a dois sentidos que se encontraram e se contactaram. Não pode haver "sentido em si" ele só existe para outro sentido, isto é, só existe com ele. Não pode haver um sentido único (um). Por isso não pode haver o primeiro nem o último sentido, ele

\footnotetext{
${ }^{3}$ Uma versão dessa reflexão foi apresentada no VIII Colóquio Internacional de Filosofia e Educação, $\mathrm{RJ}, 2016$, cujo texto foi publicado nos anais do evento.
} 
está sempre situado entre os sentidos, é um elo na cadeia dos sentidos, a única que pode existir realmente em sua totalidade. $\mathrm{Na}$ vida histórica, essa cadeia cresce infinitamente e por isso cada elo seu isolado se renova mais em mais, como que torna a nascer (BAKHTIN, 2011, p.382).

A sensibilidade é um patrimônio de todos os seres humanos, "ainda que em diferentes graus ou talvez em áreas sensíveis diferentes, todo ser humano que nasce, nasce com um potencial de sensibilidade" (OSTROWER, 1987, p.12). Em cada ato transparece a projeção de uma ordem interior que interpreta os fenômenos em busca de sentidos que serão relacionados, ordenados, configurados e significados. Esse movimento explicita a profunda motivação humana de criar que ocorre na esfera da intuição. "O homem só pode crescer, enquanto ser humano, coerentemente, ordenando, dando forma, criando", destaca Ostrower (1987, p. 12), que completa:

As diversas opções e decisões que surgem no trabalho e que determinam a configuração em vias de ser criada, não se reduzem a operações dirigidas pelo conhecimento consciente. Intuitivos, esses processos se tornam consciente na medida em que são expressos, isto é, na medida em que lhes damos uma forma [...] Entendo-se que a própria consciência nunca é algo acabado ou definitivo. Ela vai se formando no exercício de si mesma, num desenvolvimento dinâmico em que o homem, procurando sobreviver e agindo, ao transformar a natureza se transforma também. $E$ o homem não somente percebe as transformações como sobretudo nelas se percebe (OSTROWER, 1987, p. 10).

É com esse olhar que se consolida o Projeto Arqueologia de Saberes, Imagens e Afetos, uma experiência que abriga as práxis de sensibilidades ${ }^{4}$, que se constituem em atos pedagógicos de resistência ao silenciamento da reflexão, de valoração da potência instauradora de sentidos e histórias, promovedora do desvelamento de subjetividades, geradora de fluxos de imagens e objetos, narrativas escritas e orais, construídas no tempo e no espaço da disciplina Arte e Educação. Em questão, um marcador de página apropriado no evento ArtRio, em 2014, no Rio de Janeiro, confeccionado em papel cartão e que reproduz a imagem de um desenho da artista plástica e escritora Sonia Lins (1919-2003). O objeto, além de cumprir a função a qual se destina no cotidiano, também é um suporte de divulgação do museu virtual (www.sonialins.com.br) da artista, reunindo a sua obra literária e visual, documentos, informações sobre a sua vida e depoimentos em vídeo de seus

\footnotetext{
${ }^{4}$ Práxis de sensibilidades são atividades, exercícios, projetos e/ou propostas sugeridas no contexto da disciplina Arte e Educação que objetivam encarnar o discente de sua mitopoética, desvelar subjetividades e valorizar processos de criação.
} 
DOI: $10.12957 /$ e-mosaicos.2018.30124

contemporâneos. Na frente, o que chama a atenção é a imagem da cabeça de uma mulher cujos cabelos e rosto são desenhados com a palavra "eu"; no verso, juntamente com o endereço do website, há o seguinte registro: "Há espelhos que gostam de nós. E outros que nos confundem com a mãe da gente.

Figura 1 - Imagem gráfica do marcador de texto inspirado na obra da artista Sonia Lins

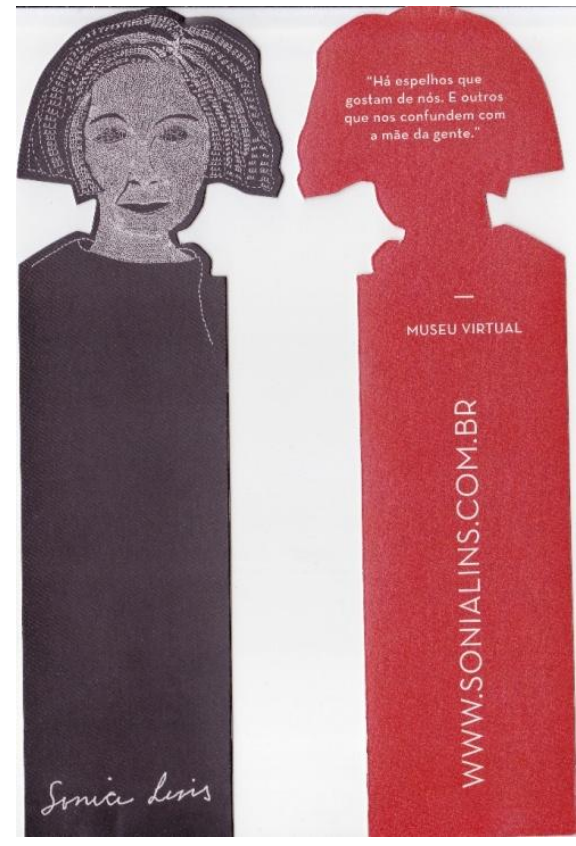

Fonte: www.sonialins.com.br

Ao entregar aos discentes o objeto, desconhecia a obra da artista e sua trajetória, o que interessava, naquele instante, era que cada estudante constituísse uma jornada de criação em torno do marcador de texto. Esse exercício estava comprometido com a irrestrita liberdade de apropriação e ressignificação da sua materialidade e função dentro da lógica de uso e consumo. Combinamos que, juntamente com a apreciação coletiva do objeto, imagem, projeto e/ou ideia concretizada em acontecimento estético, haveria uma apresentação individual que explicitasse 0 percurso, as motivações e as escolhas que permearam o processo criativo, também na ocasião, seria entregue uma narrativa que apresentasse todo o conjunto de outros sentidos gerados a partir do marcador de página inspirado em uma obra da artista Sônia Lins.

O aspecto relevante a ser considerado é que, por meio dessa nova materialidade do objeto, se concretizou um conteúdo expressivo e sensível. "A forma converte a expressão subjetiva em comunicação objetivada. Por isso, o formar, o criar, é sempre um ordenar e comunicar" (OSTROWER, 1987, p. 24). O que apresento é um recorte dessas narrativas surpreendentes que dialogam diretamente com o pensamento de Benjamin, Ostrower e Bakhtin e também se insere no debate 


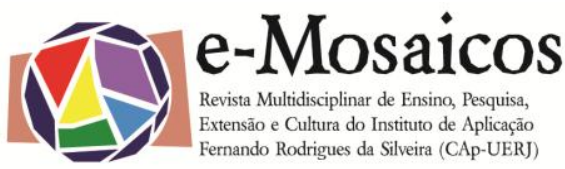

DOI: $10.12957 /$ e-mosaicos.2018.30124

que envolve uma pedagogia ancorada nos desafios que a arte contemporânea lança ao público em geral e, em particular, ao contexto institucional voltado à formação inicial de professores, visto que o olhar discente ainda se vincula ao cânone renascentista que geometriza a representação espacial com a perspectiva linear, 0 que proporciona à arte uma apurada ilusão da realidade. A arte contemporânea gera desconfiança e medo por ser abrangente demais e muito próxima das experiências cotidianas da vida.

Ainda, antes de adentrarmos nessa experiência sensível, as narrativas ${ }^{5}$ apresentam uma diversidade de olhares e capturas simbólicas do objeto, e 0 conjunto selecionado revela uma exposição sutil de um universo subjetivo, particular, íntimo, e, também, um processo artesanal de criação. Confidências, reminiscências, sentimentos, conflitos e devaneios são partilhados com uma sinceridade tocante. Ao invés de costurá-las com as intervenções teóricas dos nossos autores privilegiados, apresento-as em bloco, pois acredito que asseguro, desta forma, a unidade poética de um pensamento e a sua expressão pedagógica. Também cabe destacar que aqui se encontra um pequeno recorte de uma experiência que reuniu cerca de setenta discentes matriculados na disciplina Arte e Educação, ministrada no $1^{\circ}$ período, nos turnos da manhã, tarde e noite.

O Projeto Arqueologia de Saberes, Imagens e Afetos se inspira livremente na proposta metodológica e pedagógica formulada pelo colombiano Orlando Fals Borda (2010): Pesquisa-Ação Participativa (IAP). Os fundamentos que a regem e se entrelaçam com a experiência em curso evidenciam pontos em comum: realizar esforços coletivos de indagação científica nos quais se aplicam princípios gerais de observação e inferência; recuperar e reinterpretar a história esquecida ou tergiversada; valorizar as raízes incorporando e reinterpretando elementos da cultura das classes populares e do saber cotidianos, da arte e da ciência popular; unir o elemento sensível ao inteligível. É uma metodologia, em suma, que se constrói no acontecimento, se estrutura no frigir do encontro com o cotidiano e na expressão da sua imponderabilidade. Ainda cabe destacar que o Projeto em questão e as práxis de sensibilidades objetivam investigar e ampliar os sentidos e o lócus da arte em um curso voltado à formação inicial de professores e afirmam, como princípio primevo, que todo olhar está impregnado de uma existência sensível.

\section{NARRATIVAS: O ENCONTRO COM SONIA LINS E O MARCADOR DE PÁGINA}

Ao receber o marcador de páginas, a primeira ideia que me ocorreu foi fazer algo ligado a mim mesma. Não sabia nada a respeito de Sônia Lins, mas tinha certeza de uma coisa: se ela estava em

\footnotetext{
${ }^{5}$ Optou-se pelo anonimato das narrativas, constam apenas as iniciais dos estudantes porque há aspectos éticos que não estão totalmente claros para o autor, algumas foram editadas devido ao seu tamanho excessivo, contudo se preservou a coerência e a clareza das narrativas que parcialmente foram revisadas, uma opção ética e político-pedagógica que assegura a natureza singular e a expressão da palavra escrita do discente.
} 
evidência por certo se tratava de alguém que tinha alguma representatividade com o mundo da arte. Então como já era minha intenção, transformei o marcador de texto em uma mulher, pensei em fazer um autorretrato. Não sei se Ela é uma mulher negra, mas senti uma grande identificação com Ela. Como o marcador de texto é de cor preta, coloquei o cabelo também de cor preta, comecei a pensar como seria essa roupa, a cor, o tecido, e, por tratar-se de mim mesma, teria que ser uma vestimenta de acordo com o meu estilo. Não sei desenhar, então comecei a montá-la com recortes de papel e colagem. Ao olhar esse marcador, me veio à mente a imagem de uma mulher forte, guerreira, determinada, que de alguma forma conseguiu se destacar entre tantos seres humanos, a ponto de ser citada na realização de uma trabalho ligado à disciplina Arte e Educação. Eu me identifiquei com esta mulher, no sentido de também ser forte, determinada e guerreira, que também corre atrás dos seus objetivos sem desistir jamais diante das dificuldades que a vida me apresenta (A.R.S.R).

No dia da entrega do marcador sabia bem o que fazer, seria sobre a viagem que faria no dia seguinte, um lugar onde me esforçarei o bastante para passar o resto da minha vida, um lugar tranquilo, bonito, um paraíso para mim. Chegando lá não me cansei de procurar algo que o representasse, foi quando olhei para o mar e vi que não era um dia bom para ele, estava agitado, algo o deixara daquele jeito, não sabia o que era, mas vinham em mim todas as possibilidades: será o tempo? O sol não sorria naquele dia. Será a poluição que o ataca? Por todo lado garrafas e copos que ele já tinha trazido à beira. Não conseguia chegar a uma conclusão sobre o que o deixará daquele jeito, foi quando olhei para baixo e vi uma concha, linda por sinal, mas quando decidi olhar para frente lá estava ele bravo, agitado, querendo tirar algo muito especial de mim. Daí deixei de lado aquela concha e o desespero me dominou. Vendo o mar com tanta raiva, me fez ver que ele não é tão dócil assim, parecia uma mãe em fúria, naquele momento ele me refletiu um mar que não conhecia. Foi quando o desespero acabou e percebi que não conseguia encontrar mais nada que o representasse de maneira que eu o conhecia ou achava que conhecia, a surpresa foi tão grande que não o reconhecia mais, a viagem para mim acabou naquele instante. Retornei a pensar no que iria fazer com o trabalho, não queria mais representar o mar, mas não parava de pensar naquele momento de raiva dele e nos planos de associar meu último trabalho do semestre com o paraíso que tinha criado com o mar, então surgiu a ideia de fazer o pôr do sol no mar negro, porque foi isso que ele me mostrou. Ele é azul, é lindo, mas também pode ser negro e traiçoeiro. Há águas que gostam de nós. E outras que nos confundem com a mãe da gente (M.B.R.L). 
Biofotografia, marcador, páginas da vida - Esse trabalho serve para explorar a imaginação, pois não há regras a serem seguidas, mas há uma regra que é criar um projeto a partir do marcador. Com isso, para desenvolver o meu pensamento, busquei algumas referências no próprio marcador. O que me chamou a atenção foi a palavra EU no cabelo. Essa palavra começou a aguçar a minha mente, logo surgiu a ideia do projeto do meu trabalho: criar uma biofotografia. Para criá-lo, busquei alguns materiais tais como: cartolina, papel glacê, cola, impressões e criatividade. Não busquei referência e nenhum trabalho como fonte de pesquisa, muito menos entrar no site da própria Sonia Lins para não ser "contaminado" com alguma informação adicional, pois pesquisar no meu EU foi a fonte da minha inspiração para a execução do trabalho. Como a finalidade de um marcador é identificar a página que o usuário está para que não se perca no decorrer de alguma história, cada um é o seu próprio marcador de sua própria história. Têm histórias que marcam, têm histórias que passam, mas todas deixam uma marca [...] A biofotografia não é um simples álbum de impressão. É um conjunto de momentos de cada EU que marcam a trajetória de uma história de vida [...] Lembrando que a biofotografia é um objeto muito valioso, pessoal e intransferível e cada um registra a sua própria história, pois o objetivo do marcador contido nele é registrar as páginas da vida e essas são páginas que não poderão ser arrancadas depois de impressa (F.M.S.).

Primeiramente, quando recebi a tarefa proposta pelo professor fiquei encarando-a com uma expressão dupla, vazia e cheia ao mesmo tempo. Vazia porque não tinha ideia do que fazer como expressão artística e cheia porque estava repleta de dúvidas acerca da proposta. Estes questionamentos me levaram a guardar o marcador dentro do meu caderno e esquecê-lo por alguns dias [...] Primeiro, como não a conhecia, assim como ninguém, decidi que cortaria o objeto em formato de ponto de interrogação. Assim, estaria representando o meu momento de desconhecimento acerca da pessoa que está representada no objeto, além de expor minha confusão mental sobre o que fazer. Estava decidido, seria isso e estava pronta para executar o plano. Sentei, peguei o marcador, uma caneta permanente por ser mais escura e a tesoura. Então fiquei olhando o marcador e reparei que havia detalhes nele que eu não havia reparado anteriormente, como por exemplo, o fato da representação feminina, na parte superior, ser composta totalmente pelo vocábulo "eu" [...] O eu é composto por diversos "eus" interiores. Cada atitude que você toma, cada decisão, cada sentimento que o rege, compõe esse eu majoritário. A mulher me passa a impressão de ter um semblante ora sério, ora entristecido. 
Por está razão, decidi, como minha expressão artística, aproveitar o corpo do marcador de páginas e utilizá-lo como uma continuação desta mulher. Para isso, pensando no semblante dela, resolvi usar os espaços vazios do que seria o corpo dela para escrever palavras que aparecem constantemente na sociedade atual e que nos deixam tristes por acontecerem conosco ou com pessoas do nosso convívio. No verso do marcador de páginas escrevi a frase "somos todos iguais" (L.R.B.).

Minha Arte - Faz tempo que não escrevo algo que eu tenha feito. Em geral, tenho me ocupado escrevendo sobre o que pesquisei, o que li, o que estudei. Mas acho que sobre as minhas ações, desde que "cresci" e virei adulta, não escrevi mais. Ao ver o marcador de páginas, instantaneamente, lembrei das minhas perdas esse ano, minha avó e dois tios. Talvez seja pela cor preta na frente, pelo "rosto" constituído de uma senhora no topo, não sei. Mas ao virar, encontrei a cor vermelha, eu sou apaixonada pela cor vermelha, roupas vermelhas, batom vermelho [...] Tendo esse misto de sensações ainda misturado dentro mim, optei por recortar três corações, não corações em real anatômicos e sim corações que ensinamos as crianças a desenhar, corações que recebemos em cartinhas de amor (G.P.).

Ao olhar para o marcador com a cabeça de mulher, identifiquei a palavra "eu" escrita repetidamente dando forma aos seus cabelos encaracolados. Também pensei em dar vida a essa cabeça, dando-Ihe corpo e alma. Com a tesoura fiz o recorte da silhueta, dando-lhe corpo a partir do retângulo do marcador. Com a cola e purpurina fiz a boca e o coração com a cor vermelha, dando-Ihe vida. Aproveitando o enredo do "eu", estampei a perna esquerda da calça com essa palavra com a purpurina prata. A perna direita foi preenchida com as sobras de purpurina prata e vermelha caída sobre a mesa. Com caneta prata finalizei o pesponto da blusa e para finalizar escrevi a palavra "VIDA" em sua blusa. Eis minha mulher de corpo e alma que quis dizer: - "Eu estou viva" (J.M.B.).

A primeira impressão e ideia que tive foram de vendar os olhos da face da figura apresentada no marca páginas. A intenção é expressar o que sinto a respeito do mesmo: é um objeto até então desconhecido, não sei o que representa nem do que se trata (esse é o significado da venda nos olhos), mas, ao mesmo tempo, me toca de alguma forma pela frase impressa que me remete à profunda reflexão sobre o espelho da alma [...] Tomo como minha percepção pessoal a ideia de que os "espelhos" citados seriam diferentes olhares de nós mesmos, por nós mesmos, em diferentes momentos e 
situações, quando em um momento gostamos do que vemos em nós mesmos e, em outro, não gostamos da imagem refletida e nos punimos por isso, semelhante a atitude de nossas mães na infância. Correção, repreensão, da forma que fomos controlados quando criança, como tinha de ser seguido por imposição, sem falhas ou questionamentos, baseado na forma "correta" de se agir.(A.G.F.V.).

Tive vontade de compor algo significativo, por entender que Sônia Lins possui várias facetas artísticas e, singularmente, seu grafismo é composto pela palavra "EU". Pensei em fotografar o marcador de vários ângulos e tamanhos, embora ainda não estivesse certa do que iria compor com as imagens, queria deixar expressa a personalidade da artista. Fotografei com a máquina do celular por ser mais simples o manuseio e fiz várias fotos com iluminação, distância e tonalidades diferentes, incluindo o negativo e o sépia. Transferi as fotos para o meu notebook e imprimi todas em papel A4 e comecei o processo de composição . Alinhei de várias maneiras as folhas impressas, porém não me agradou nenhuma delas, não achei harmônico. Procurei então melhorar a composição recortando as figuras e reposicionei em forma de procissão, o que me agradou, mas não tanto, pois com o papel A4 as figuras tinham o aspecto fosco. Lembrei que guardava algumas folhas de papel de fotografia que restaram de um trabalho do meu filho caçula e só havia cinco folhas. Então as usei para a impressão com as mesmas variantes de iluminação, distância e cor, em seguida fiz o recorte das figuras. Após tê-las cortado, colei-as num papel canson e fixei-as sob uma peça de vidro que foi colocada em cima de um bauzinho sem tampa, sendo transformado então em objeto de decoração, o que me agradou bastante. Meu processo foi tão envolvente pelas várias possibilidades experimentadas que só me dei conta que o dia amanhecia quando meu filho chegou em casa e me perguntou: - Ô mãe, você não vai dormir não? (B.S.P.).

Diferenças: a beleza de se saber que é - [...] Engraçado é que por mais que eu tentasse pensar em outras coisas, sempre retornava ao meu primeiro contato com o marcador: a palavra "eu" [...] Comecei a pesquisar sobre a autora, entrei no site, busquei algumas coisas sobre ela, conheci a obra "EU" e fiquei impressionado. A obra surgiu quando ela pegou um lápis e tentou desenhar a própria digital escrevendo várias vezes a palavra eu, a partir dali surgiram vários desenhos feitos dessa forma por essa artista plástica [...] Porém o trabalho que o professor pediu era meu e sobre a minha expressão de arte e não sobre ela. Foi aí que comecei a pensar novamente e percebi uma coisa, esse já era eu. Quando eu, ao contrário de outros alunos, decidi pesquisar, quando decidi arriscar a minha expressão conhecendo o trabalho e o porquê da artista pensar dessa forma, fiquei satisfeito em conhecer algo novo e aprender sobre a artista, 


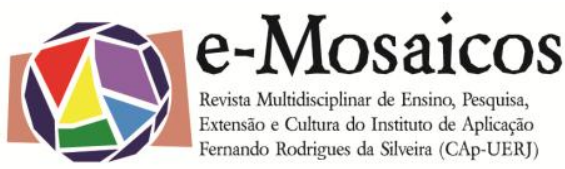

DOI: $10.12957 /$ e-mosaicos.2018.30124

nesse momento eu percebi que o bom, o diferencial de cada um de nós está exatamente nisso. Está na particularidade e na singularidade de cada um de nós. Não fazer o que maioria faz e nem tentar criar a partir do que a maioria criou, não tentar ser parecido com ninguém, mas ser apenas você mesmo [...] Encontrei a própria artista dizendo que nunca tentava fazer o mesmo desenho duas vezes, pois cada desenho é único e nunca o segundo ficaria igual ao primeiro. Ora, se desenhos podem ser únicos, o que dizer sobre o ser humano, sobre $\operatorname{mim}$ ? (D.M.P.).

\section{Cintilações e CLARÕES: OS ECOS DAS NARRATIVAS}

Escrevendo, editando e relendo estas narrativas, transparece a vontade de olhar, pensar e falar sobre educação com e através da ética, da estética, da paixão de conhecer o outro, seus afetos e os estados de criação que impulsionam o desabrochar de subjetividades e revelam "mundos" e poéticas. Esse conjunto de ações apresenta processos que forjam a produção de sentidos que qualificam o olhar para os desafios de uma educação estética na contemporaneidade. Ainda, há o desejo de pensar a educação para além das epistemologias tradicionais que dicotomizam a relação sujeito-objeto. Pensar na forma de rizoma, de acordo com a concepção de Deleuze e Félix Guattari (2011), que, com suas múltiplas entradas e pontos de fuga, se metamorfoseia em caleidoscópio. No cerne deste turbilhão de vozes está o exercício de uma humanidade que, corajosamente, refuta os valores que nos brutalizam em todos os contextos da vida e evidencia o conceito de experiência, tal como Benjamin (1994) o concebe: um feixe de luz que se conecta com os rastros e as pegadas de uma existência.

A experiência (Erfahrung), de forma inequívoca, é um importante conceito na obra do filósofo berlinense que atravessa o conjunto de sua produção ensaística e adquire ângulo e tratamento diferenciados na sua trajetória intelectual - a ela, se associa de forma outra o conceito de vivência (Erlebnis). A experiência está relacionada ao inconsciente, à tradição, à memória, individual e coletiva; a vivência aponta para uma existência privada, fechada na solidão, circunscrita ao choque e à percepção consciente. Nas sociedades modernas, o esvaziamento da experiência está relacionado a uma valoração da vivência que, aos olhos de Benjamin, é um modo empobrecido de o homem experimentar o seu habitar no mundo, não apenas no ambiente onde são estabelecidas as relações de trabalho capitalistas, mas igualmente no mundo da arte, da educação e do lazer. A experiência é um lento processo de sedimentação de várias experiências que, mesmo afastadas temporalmente, convergem, ressignificam e se fazem presentes a todo instante. Ao contrário, a vivência é uma série de presentes puros e não mais relacionados na linha do tempo.

Em um só tempo e espaço, as narrativas colocam em relevo o conceito de experiência, tal como Benjamin o descreve, e apresentam o encontro com o outro 
DOI: $10.12957 /$ e-mosaicos.2018.30124

que se materializa no marcador de página inspirado na obra da artista Sonia Lins. O conhecimento, em uma perspectiva bakhtiniana, tem caráter dialógico, é acontecimento, é encontro, portanto, podemos estender essa especificidade e considerar que o sujeito se constitui na relação com o outro. 0 homem tem uma necessidade estética absoluta do outro. Bakhtin, a partir dessa angulação, escreve:

A forma do vivenciamento concreto do indivíduo real é a correlação entre as categorias imagéticas do eu e do outro, e essa forma do eu, na qual vivencio só a mim, difere radicalmente da forma do outro, na qual vivencio todos os outros indivíduos sem exceção. $O$ modo como eu vivencio o eu do outro difere inteiramente do modo como vivencio o meu próprio eu, isso entra na categoria do outro como elemento integrante, e essa diferença tem importância fundamental tanto para a estética quanto para a ética (BAKHTIN, 2011, p. 35).

Ainda, entre os seus apontamentos de 1970-1971, encontramos uma passagem que distende essa argumentação:

Tudo o que me diz respeito, a começar pelo meu nome, chega do mundo exterior à minha consciência pela boca dos outros (da minha mãe etc.), com a sua entonação, em sua tonalidade valorativoemocional. A princípio eu tomo consciência de mim através dos outros: deles eu recebo as palavras, as formas e a tonalidade para a formação da primeira noção de mim mesmo (BAKHTIN, 2011, p. 37374).

O pensador russo afirma que o homem na arte é um homem integral e, no campo da comunicação estética, a interação com a obra de arte é um processo ativo e criativo que é continuamente recriado por meio da cocriação do sujeito no processo de fruição estética. Podemos considerar que não existe a primeira nem a última palavra, não há limites para a produção de enunciados. Neste sentido, a comunicação estética se renova em seu próprio inacabamento, instaurando inscrições e deslocamentos de tempos, lugares, vozes e corpos. A própria arte é uma fronteira, uma trama de fricções: um entre lugares, um entre eu e o outro, um entre outros múltiplos. O artístico, diz Bakhtin, não se localiza nem no objeto nem nas psiques do criador e contemplador consideradas separadamente; ele contém essas três instâncias. Sem um sujeito que contempla, a obra e o autor não permanecem na história.

As narrativas que afloram a partir do encontro com o marcador de página espelham a tríade que Bakhtin apresenta como indissociável e poeticamente vinculada. O Projeto Arqueologia de Saberes, Imagens e Afetos aciona uma 
DOI: 10.12957/e-mosaicos.2018.30124

diversidade tão grande de enunciados que é possível pensar e relacionar a partir de várias veredas, não há um único ponto de contato. É dobra na concepção de Deleuze: "A matéria-dobra é uma matéria-tempo, cujos fenômenos são como a descarga contínua de uma infinidade de arcabuzes ao vento" (1991, p.19). O múltiplo, nas palavras do filósofo francês, não é só o que tem muitas partes, mas o que é dobrado de muitas maneiras. A dobra é potência como condição de variação e como ato, é o ato da dobra. É contemporâneo na concepção de Giorgio Agamben (2009, p. 72):

[...] o contemporâneo não é apenas aquele que, percebendo o escuro do presente, nele aprende a resoluta luz; é também aquele que, dividindo e interpolando o tempo, está á altura de transformá-lo e de colocá-lo em relação com os outros tempos, de nele ler de modo inédito a história [...].

Há uma afinidade, na citação de Agamben, com as reflexões de Benjamin, principalmente em seu último escrito, as Teses Sobre o Conceito da História, de 1940.

Benjamin insistiu em uma apreensão do tempo histórico em termos de intensidade e não de cronologia. A noção de origem, como experiência filosófica do tempo e da verdade, deve servir de base a uma historiografia regida por outra temporalidade que não mais se arregimenta em uma causalidade linear, exterior ao evento. Jeanne Marie Gagnebin (2004) ressalta que a origem benjaminiana, mais que um projeto restaurativo ingênuo, é uma retomada do passado, mas ao mesmo tempo abertura sobre o futuro, inacabamento constitutivo. $E$ justamente aquilo que escapa à classificação que se torna indício de uma verdade possível. O rabino marxista ${ }^{6}$ desconfia dos valores médios e se consagra pacientemente à análise do atípico. O confronto essencial da origem com a história é o tema-chave de sua filosofia. A rememoração do passado não implica simplesmente a restauração do passado, mas, sobretudo, uma transformação do presente tal que, se o passado for reencontrado, não fique o mesmo, seja retomado de "modo inédito", como diria Agamben.

A consciência de fazer explodir o continuum da história, através de uma experiência, é tarefa do historiador materialista e é assim que se constitui o objeto histórico. Indica-nos Benjamin (2006, p. 517):

A historiografia materialista não escolhe aleatoriamente seus objetos. Ela não os toma, e sim os arranca, por uma explosão, do curso da

\footnotetext{
${ }^{6}$ Compreende parte do título de um capítulo ("O Rabino Marxista: Walter Benjamin") do livro $A$ Ideologia da Estética em que Terry Eagleton analisa a estética de Walter Benjamin no contexto do marxismo.
} 
e-Mosaicos - Revista Multidisciplinar de Ensino, Pesquisa, Extensão e Cultura do Instituto de Aplicação Fernando Rodrigues da Silveira (CAp-UERJ) V. 7 - N. 14 - ABRIL 2018 - ISSN: 2316-9303

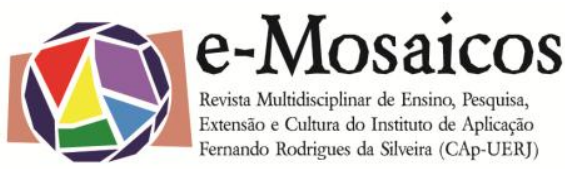

DOI: $10.12957 /$ e-mosaicos.2018.30124

história. Seus procedimentos são mais abrangentes, seus acontecimentos mais essenciais $\left[\mathrm{N} 10^{\mathrm{a}}, 2\right]$.

A ideia de um despertar está presente em sua concepção e apresentação da história, e a imagem é a categoria central da teoria benjaminiana da cultura, pois possibilita o acesso a um saber arcaico e a formas primitivas de conhecimento. Por meio de imagens, que atuam no fluxo da consciência e do inconsciente, é possível compreender a mentalidade de uma época. Em outras palavras, a produção de conhecimento da história se dá na superfície do seu tempo, ou seja, nas imagens do cotidiano, do desejo, no seu aspecto residual e matérico e na moldura de suas fantasmagorias. Desvendar essas imagens e expressá-las dialeticamente é a tarefa do historiador materialista. Neste sentido, as narrativas discentes, que brotam do diálogo com marcadores de página, falam de um despertar para o que está na superfície do nosso tempo e incorporam o manejo com qual o historiador materialista lida com as imagens do cotidiano.

\section{Palavras finais}

O discurso contemporâneo trata de uma "morte da história da arte" em função tanto da falência do universalismo da história como narrativa legitimadora como do aparecimento de outro conjunto de práticas artísticas que exorta a uma mudança de discurso, já que o objeto de fruição estética não se ajusta mais aos seus antigos enquadramentos. $\mathrm{O}$ fim da história da arte não significa que a arte e a ciência da arte tenham alcançado o seu fim, mas registra o fato de que na arte, assim como no pensamento da história da arte, delineia-se o fim de uma tradição, que desde a modernidade se tornara o cânone na forma que nos foi confiada. $\mathrm{O}$ fim da história da arte não é o fim da arte, é o fim da narrativa de uma cultura histórica linear e unívoca. $O$ contemporâneo, neste sentido, se afirma como um campo de narrativas que rompem a linearidade, o que está em jogo são os princípios da multiplicidade e alteridade (BELTING, 2006).

O encontro com o marcador de página, com a obra e o pensamento de Sonia Lins, foi sendo desenhado na afluência perceptiva e poética do eu no encontro do outro e dos vários outros, justamente na superfície do nosso tempo, em um objeto prosaico, enunciados foram extraídos de um mergulho sensível no micro, não como um fragmento do macro, mas como uma síntese provisória dele. Como nos sugere Deleuze (2003), o ato de pensar é a única criação verdadeira e mais importante do que o pensamento, é aquilo que nos força a pensar, o que é relevante, de fato, é o percurso, a processualidade, e não o ponto de chegada ou o resultado final. A potência dessa experiência apresenta uma estética que é menos artística e mais da nossa existência. Reminiscências vêm à tona, pegadas e rastros vão sendo inventariados e contam um percurso de criação. No cerne, o desafio de encarar a contemporaneidade na sua riqueza de perspectivas, de mundos possíveis que 
DOI: $10.12957 /$ e-mosaicos.2018.30124

exaltam nossa experiência de contato com o que está fora, mas não separado de nós.

\section{REFERÊNCIAS}

AGAMBEN, Giorgio. O que é o Contemporâneo? E Outros Ensaios. Santa Catarina: Argos, 2009.

BAKHTIN, M. Estética da Criação Verbal. São Paulo: Martins Fontes, 2011.

.; VOLOSCHINOV, V. N. Discurso na vida e discurso na arte. (1926) Trad. De Cristóvão Tezza. Disponível em http://www.uesb.br/ppgcel/Discurso-Na-VidaDiscurso-Na-Arte.pdf, acessado em 15 de março de 2016.

BELTING, Hans. Fim da História da Arte - uma revisão dez anos depois. [trad. Rodnei Nascimento] São Paulo: Cosac \& Naify, 2006.

BENJAMIN, Walter. A Origem do drama barroco alemão. Trad. S. P. Rouanet. São Paulo: Editora Brasiliense, 1984.

. Obras Escolhidas. Trad. S.P. Rouanet. São Paulo: Brasiliense, 1994, v.1. .Passagens. Sao Paulo: Editora UFMG, 2006.

CORSINO, Patrícia. Benjamin e Bakhtin: outros tempos e novos caminhos para pesquisa em Educação. In: LEITE, Miriam \& GABRIEL, Carmen Teresa (org) Linguagem, Discurso, Pesquisa e Educação. Rio de Janeiro: DP\&A, 2015.

D'ANGELO, Martha. Arte, política e educação em Walter Benjamin. São Paulo: Edições Loyola, 2006.

DELEUZE, Gilles. Proust e Os Signos. Rio de Janeiro: Forense Universitária, 2003. .A Dobra: Leibniz e o Barroco. São Paulo: Papirus, 1991 .Conversações. São Paulo: Editora 34, 2013. .; GUATTARI, Félix. Mil Platôs. Rio de Janeiro: Editora 34, 2011, vol 1.

EAGLETON, Terry. A Ideologia da Estética. Rio de Janeiro: Editora Jorge Zahar, 1993.

FALS BORDA, ORLANDO. Da pedagogia do oprimido à pesquisa participativa. In: STRECK, Danilo R (Org). Fontes da Pedagogia Latino-Americana: uma antologia. Belo Horizonte: Autêntica Editora, 2010. 
DOI: $10.12957 /$ e-mosaicos.2018.30124

. Pesquisa-Ação, ciência e educação popular nos anos 90. In: STRECK, Danilo R (Org). Fontes da Pedagogia Latino-Americana: uma antologia. Belo Horizonte: Autêntica Editora, 2010.

GAGNEBIN, Jeanne Marie. História e Narração em Walter Benjamin. São Paulo: Editora Perspectiva, 2004.

KRAMER, Sonia. Por entre as Pedras: Arma e Sonho na Escola. São Paulo: Editora Ática, 1993.

LOWY, Michel. Romantismo e Messianismo: ensaios sobre Lukács e Benjamin. São Paulo: Perspectiva, 1990.

. Walter Benjamin: aviso de incêndio: uma leitura da teses. São Paulo:

Boitempo, 2005.

MURICY, Kátia. Alegorias da dialética: imagem e pensamento em Walter Benjamin. Rio de Janeiro: Relume Dumara, 1998.

OSTROWER. Fayga. Criatividade e Processos de Criação. Petrópolis: Vozes, 1987.

RIBETTO, Anelice (org.). políticas, poéticas e práticas pedagógicas (com minúsculas). Rio de Janeiro: Lamparina, 2014.

SAMPAIO, Carmen Sanches. Narrativas docentes: visibilidade de saberes e fazeres alfabetizadores na socialização da prática pedagógica cotidiana. EDUFF . No prelo

SOUZA E JOBIM, Solange. Mikhail Bakhtin e Walter Benjamin: Polifonia, Alegoria e o Conceito de Verdade no Discurso da Ciência Contemporânea. In: BRAIT, Beth (Org) Bakhtin, Dialogismo e Construção do Sentido. São Paulo: Editora da Unicamp, 1997.

Recebido em 24 de agosto de 2017. Aceito em 22 de fevereiro de 2018. 